\title{
A Sociological Analysis of Bhojpuri Jhoomar in Mauritius
}

\author{
Jayganesh Dawosing \\ Lecturer, Department of Bhojpuri, Folklore \& Oral Traditions \\ Mahatma Gandhi Institute, Moka, Mauritius
}

\begin{abstract}
To ensure a significant place among both the local and international Bhojpuri singers, the singers keep reproducing the cultural content of this type of Bhojpuri songs, called the 'Jhoomar' which literally means dancing in a circular motion. However, in this process of cultural evolution, the fear of either preserving the traditional or digressing from the latter will always be there. This paper deals with the sociological analysis of jhoomar songs of the present generation who create new lyrics in the Mauritian Bhojpuri songs. For entertainment purposes, some singers, at times, interpret the traditional forms in an expression of personal or group identity. The recent albums of certain of the artistes deal with contemporary issues, true to an articulation of social hierarchies, most notably race, gender and class. In correspondence to contemporary issues, a research question arises with the preservation of traditional form, how do the contemporary songs relate to broader social distinctions, especially class, race and gender? Fieldwork with local Bhojpuri singers has helped in understanding the significance of the study. This paper argues from a conceptual analysis of popular cultural significance of the study. The content of these jhoomar songs are relevant in culture and music of the 21st century, entailing fascinating issues of discussion.
\end{abstract}

Keywords: Jhoomar, Sociological Analysis, Mauritian, Bhojpuri, Folksongs

\section{INTRODUCTION}

The study of the sociology of music has become vibrant in the recent decades. People want to be creative with the traditional music. The Bhojpuri folk songs are very popular in Mauritius. In each occasion, especially during a Hindu wedding, the Bhojpuri folk songs have an importance place. women's folksong genres can be analysed such as jatsaari, ropani, sohani, jhumar and kajri. These folksongs are accounts of Bhojpuri women's everyday life. Work songs like jatsaari, ropani and sohani are melancholic in their mood, meter and tone. They are 'narratives of lament' sung by a left behind wife for her migrant 'absent husband'. Jhumar and kajri, because of their happy performance contexts, are playful.(Singh A, ) The Jhoomar song also called as 'Jhumar' or 'Jumar' are sung especially during the Geet Gawai which is a pre-wedding ceremony of Bhojpuri speaking people of Indian descent in Mauritius. (Boodhoo, 1993) In 2016, this ritual was added to the UNESCO's Intangible Cultural Heritage List.

The songs, the music, the dances are very lively. According to the tradition, men were not invited to join in as it was a private space and friendly moments shared among women only. (mymoris.mu). 
Nowadays, things have evolved. Men do form part of it either as performers or musicians and at times, as both!

Through oral transmission from one generation to the other, Jhoomar songs have been well preserved in the island. According to Sarita Boodhoo, Bhojpuri expert in Mauritius, wrote in 'Kanya Dan' (1993), in Rajasthan, it is known as ghumar from ghumna-to turn round. The origin may be same. It is sung by a group of women to accompany a circle dance of women only. Jhoomar is both a dance and a song. In fact, it is the most popular song of the Bhojpuri Geet Gawai where the dancers would dance in a circular motion. Nowadays, even youngsters can sing these songs and perform that ritual. It is both a cultural and social event where the group perform to promote and preserve the richness of the Bhojpuri culture and traditions.

\section{CONTEXT AND METHODOLOGY}

\subsection{Samplings}

For my paper, I have chosen four recent Bhojpuri folk songs commonly sung during the Geet Gawai ceremony in Mauritius in the Jhoomar category. In fact, I have analysed some ten of them from the book of Sanskaar Manjari of Suchita Ramdin.

However, I will be taking only four here which are summarized in the following table:

Table 1: Details of the Selected Songs to be Analysed

\begin{tabular}{|c|c|c|}
\hline Song Title & Source & Type of song \\
\hline 1. St Paul se al ba & Aditya Goorvadoo & Jhoomar/Bhojpuri Folk song \\
\hline 2. Lecourse khele gaila Raja & Mrs Devi Manaram & Jhoomar/Bhojpuri Folk song \\
\hline 3. Sab sakhiyan ke leke & Mrs Anumada Aukhez & Jhoomar/Bhojpuri Folk song \\
\hline 4. Age Misie Zorz & Mrs Anumada Aukhez & Jhoomar/Bhojpuri Folk song \\
\hline
\end{tabular}

\subsubsection{Critical Discourse Analysis (CDA):}

\subsection{THEORETICAL FRAMEWORK}

Following recent trends in Critical Discourse Analysis (CDA) (Machin 2010, van Leeuwen 2012; Machin and Mayr 2012; Gomez 2019), it can be said that songs may spread ideological beliefs in such a way that they reach a wider audience because of the combination of different semiotic resources, that is text, music and image.

CDA comprises of three dimensions (Fairclough, 1990). The first dimension is discourse as text relating to choices and patterns in vocabulary, grammar and text structure.

The second dimension is discourse as discursive practice, i.e. discourse as something which is produced, circulated, distributed, and consumed by society.

Finally, the last dimension is discourse as social practice, that is, the ideological effects and hegemonic processes in which discourse is seen to operate. (Fairclough, 1992a, p.93)

"We shall overcome" A Humanity Song by Roger Waters: Critical Discourse Analysis concluded that critical discourse analysis is a discourse which analyses the use of language in three different 
Dawosing, J. (2020). A Sociological Analysis of Bhojpuri Jhoomar in Mauritius. Advances in Social Sciences Research Journal, 7(5) 230-239.

dimensions and that discourse is a part of the discourse which arises in a social community (Waters, 2018).

This discourse in social community is also present in the Bhojpuri folk songs and the objects of discourse analysis can be respectively, writing, discourse, writing, conversation and communicative event. Hence, the Mauritian Jhoomar songs have interesting components to be analysed with the above lens.

\subsubsection{Fieldwork: Participant Observation and Interviews}

In order to have an in-depth knowledge of the Bhojpuri jhoomar songs, I attended five pre-wedding ceremonies known as the Geet Gawai. I also interviewed the Githarinn (female folk singers) about their experiences and views on the evolution of this particular form of folk song in the recent years. I will discuss this in the coming part.

\subsection{Analysis of song No 1}

\section{ANALYSIS AND DISCUSSION}

Table 2: Song No.1 with translation

\begin{tabular}{|c|c|}
\hline Lyrics & Translation \\
\hline St Paul se aal ba nachanya & The dancers have come from St Paul \\
\hline Hum ta jhumar gaai janila & $\begin{array}{l}\text { And they know how to sing the Bhojpuri folk songs well! } \\
\text { Come! Dance with me my dear! }\end{array}$ \\
\hline Chal Goriya hamar sange nachle & Yakshini Jalsa Group has come to entertain you! \\
\hline Yakshini Jalsa pu met nissa & Get ready to put your money in the water container! \\
\hline
\end{tabular}

This song is based on the place from where the group has come from. It gives a geographical indication about their local address so that those attending the function will have an idea from where they are from. I have interviewed Mr Aditya Goorvadoo who is 22 years old and resides at St Paul, Mauritius. He told me that he has uses some traditional words with some of his own and has composed the above song. It is also a way of introducing his group to the audience and also advertising his group.

Besides, the Geet gawai is no longer perform on a voluntary basis as used to be the case in the eighties and nineties. Nowadays, it has become sustainable and the artistes are paid to do it.

That is why, Aditya, composed these lines in creole: Yakshini jalsa pu met nissa, prepare zot cash pu met dan lota-Yakshini Jalsa Group has come to entertain you. Get ready to put money in the water container.' During his interview, he confessed that presently they charge some Rs 8000 (219 USD) excluding the transport for some 10 to 15 participants. He has been singing these songs since childhood and has learnt them from another friend of his. It is already five years now since he sings and dances in the Geet Gawai. At times, he even dresses himself as a damsel tearing the dance floor with his other male friends who would equally dress up like girls and perform.

Furthermore, all possible means of advertisement are used by each of the informants interviewed: Facebook, WhatsApp, Visiting cards, Instagram, Twitter. All the participants interviewed have their Facebook pages. They are to be booked well in advance to ensure their participation in a wedding. 


\subsection{Analysis of song No.2: Sab sakhiyan ke leke}

Table 3: Song No.2 with translation

\begin{tabular}{|c|c|}
\hline Lyrics & Translation \\
\hline Sab sakhiyan ke leke jeux des iles dekhe gaili & All my friends accompanied me to see the Indian \\
\hline Sab sakhiyan kene kene hogal par gaili akele & Ocean Island Games \\
\hline Khilari se dilwa mora lage & Where are they gone? I am left all alone \\
\hline Sab sakhiyan ke leke Caudan ghume gaili & All my friends came to stroll with me at Caudan \\
\hline Sab sakhiyan kene kene hogal par gaili akele & Where are they gone? I am left all alone! \\
\hline Sofer se dilwa mora lage & And now I have fallen for the driver! \\
\hline Sab sakhiyan ke leke lecourse dekhe gaili & $\begin{array}{l}\text { All my friends came with me to the horse racing. } \\
\text { Where are they gone? I am left all alone! }\end{array}$ \\
\hline Sab sakhiyan kene kene hogal par gaili akele & And now, I have fallen for the Jockey! \\
\hline Sab sakhiyan ke leke airport dekhe gaili & $\begin{array}{l}\text { All my friends accompanied me to see the airport. } \\
\text { Where are they gone? I am left all alone! } \\
\text { And now, I am in love with the Pilot! }\end{array}$ \\
\hline $\begin{array}{l}\text { Sab sakhiyan kene kene hogal par gaili akele } \\
\text { Pilot se dilwa mora lage }\end{array}$ & \\
\hline
\end{tabular}

According to Mrs Anumada, this song has won the first prize in a recent Jhoomar competition in Mauritius organized by the Bhojpuri Speaking Union under the aegis of the then Ministry of Arts and Culture. After the recent election held in November this year, this Ministry has changed its appellation to Ministry of Arts, Culture and National Heritage. To be noted that the Geet Gawai has been nominated on the list of World Intangible Cultural Heritage by UNESCO in December 2016. (ich.unesco.org)

Hence, the Bhojpuri Speaking Union has been organizing various Lalna and Jhoomar Competition in Mauritius to promote the Geet Gawai not only at a national but international level as well.

In this song, one of the latest in this category, mentioned is made of four different places in Mauritius where the Githarinn said she went accompanied with her friends. And then she realizes that they have gone elsewhere, leaving her all alone. Fortunately, she then meets someone caring with whom she falls in love.

The content of Jhoomar are normally about love, trust, emotions, meeting and separation. It also deals with relevant and contemporary matters. Even in the past, the Jhoomar dealt with same issues of love, hatred, jewelry, journey etc.

In this song, mentioned is made of the 'Jeux des iles' that is the Indian Ocean Island Games which took place in Mauritius from 19 to 28 July 2019. Over two thousand athletes participated in it from 7 countries. There was a total of 14 sports. For the first time, Mauritius won the first place with 92 Gold medals. The opening ceremony held on 19 July at the Anjalay Stadium, Belle Vue Harel was very well organized. The closing ceremony after the victory of Mauritius was even more crowded and all Mauritians fervently participated in it. It did create a big wave of patriotic enthusiasm among all the Mauritians and mentioning this in a Bhojpuri folk song competition was indeed a great respect to all the players who made the island proud with their success. According to one of the 
juries of that competition, Mrs Kiran Jankee, Research Officer as well for Bhojpuri Culture at the Aapravasi Ghat Trust Fund, she mentioned that it was very clever of the lady to sing this song on this level of competition. She even brought prompt like balls, whip, steering cover during her performance which not only have entertained each and everyone but scored them the highest marks!

Le Caudan Waterfront is a place of interest in the city of Mauritius. It is a sprawling and expansive complex with shops, cafes, craft market, museums, cinema halls, and variety of options to walk around and enjoy the day for! (Richards, 2016) It is indeed a place where everyone would like to visit. Normally, there are many taxi-drivers who work in this area as tourist guide as well. Therefore, the Githarinn here, admits falling for one of them who must have been generous to her and help her find her friends!

Horse racing in Mauritius is held only at Champ de Mars in Port Louis. This is a thoroughbred horse race track. It attracts tens of thousands of people on each racing day during the racing season from late March to early December and has become the ultimate meeting place for horse lovers from all over the island and even from abroad. The track has propelled horse racing as the most popular sport and form of entertainment among the local population. People all over the island like to come to horse racing for entertainment, that is why here, the Githarinn says that together with her friends, she was here to see horse racing but they got lost and finally a jockey helped her and she fell in love with him!

It is also a place of historical value where a huge crowd gather to attend the meeting of Basdeo Bissooondoyal at the kiosk of Champ des Mars during the intense campaign of 1967 general election, because that election was to determine whether Mauritius would accede to independent or remain attached to United Kingdom forever before the election of 1968 leading to the independence of Mauritius.(Ramsurrun, 2018).

\subsection{Analysis of song No.2: Jahan Bhawji looga dhowe}

\section{Table 4: Song No.3 with translation}

\begin{tabular}{|l|l|}
\hline Lyrics & Translation \\
\hline $\begin{array}{l}\text { Lecourse khele gaila Raja more phuliya haraila } \\
\text { Mor Janicoco! Ab dil na haraiya }\end{array}$ & $\begin{array}{l}\text { Oh, my dear! You lost my nose ring in horse racing } \\
\text { today! } \\
\text { Now, do not lose my heart! } \\
\text { Lecourse khele gaila Raja more erin haraila } \\
\text { Janicoco! Ab mor dil na haraiya! }\end{array}$ \\
$\begin{array}{l}\text { Oh, my dear! You lost my earings in horse racing } \\
\text { today! } \\
\text { Now, do not lose my heart! }\end{array}$ \\
$\begin{array}{ll}\text { Lecourse khele gaila Raja more harwaa haraila } \\
\text { Oh, my dear! You lost my necklace in horse racing } \\
\text { Lecourse khele gaila Raja, mor chanwa haraile } \\
\text { Mor Janicoco! Ab more dil na haraiya! }\end{array}$ & $\begin{array}{l}\text { Now, do not lose my heart! } \\
\text { Oh, my dear! You lost my bangles in horse racing } \\
\text { today! }\end{array}$ \\
Lecourse khele gaila Raja, mor paijan haraile & $\begin{array}{l}\text { Now, do not lose my heart! } \\
\text { Oh, my dear! You lost my anklets in horse racing } \\
\text { today! } \\
\text { Now, please keep my heart safely! }\end{array}$ \\
\hline
\end{tabular}


In this Jhumar, the husband lost the ornaments of his wife in betting-horse racing and the wife is warning him to keep her heart well now.

It also describes the fondness of Hindu woman's for jewelry. It is also centered on the realities of day-to-day life.

Many families are suffering because of gambling, betting, horse racing. In search of easy mony, the men often finished by losing all his money, putting at stake even the precious jewelries of their wives.

According to the Economic impact assessment of the Mauritan horse racing industry: "In 2018, the horse racing industry was responsible for generating Rs 6.2billion in GDP, creating 2,170 jobs, equivalent to Rs 2 billion worth of labour income, and contributing to 679 of Government revenue." (supertote.mu)

A gambling addiction affects more than just the gambler. The money lost at the game is tried to be retrieve through additional betting and in the end, everything is lost. This often causes divorce in the family where children suffer the most. (Stephen Unger, 2013)

In Mauritius, 'lecourse'- horse racing is also affecting certain families. Men mostly would bet to earn easy money while others bet for fun.

In many other jhoomar songs, we do have mention of the different ornaments worn by the female figure: Kanon ke jhumka girata ta gire de.patli kamaria Dolata ta dole de( No worries if the earings are falling during my dance-let me swing my hips!)

Another jhoomar mentioning different ornaments worn is 'Aho Radha nachela, Krishna bajawe bansuria'-Radha is dancing while Krina is playing the flute.

Normally, on this song, the dancers would act like Radha and Krishna where one will play the flute and the rest would dance around her.

Another famous Jhoomar in Mauritus is 'Calcutta se chutal jahaz bhanwariya dhire chala'- the ship has left the port; o wind blow thee slowly'. The jhoomar reflects the love for jewelry of the women and gives a hint of the port of embarkation in India (Boodhoo, 1993). 
Dawosing, J. (2020). A Sociological Analysis of Bhojpuri Jhoomar in Mauritius. Advances in Social Sciences Research Journal, 7(5) 230-239.

\subsection{Analysis of song No.3: Age misie Zorz}

Table 5: Song No.4 with translation

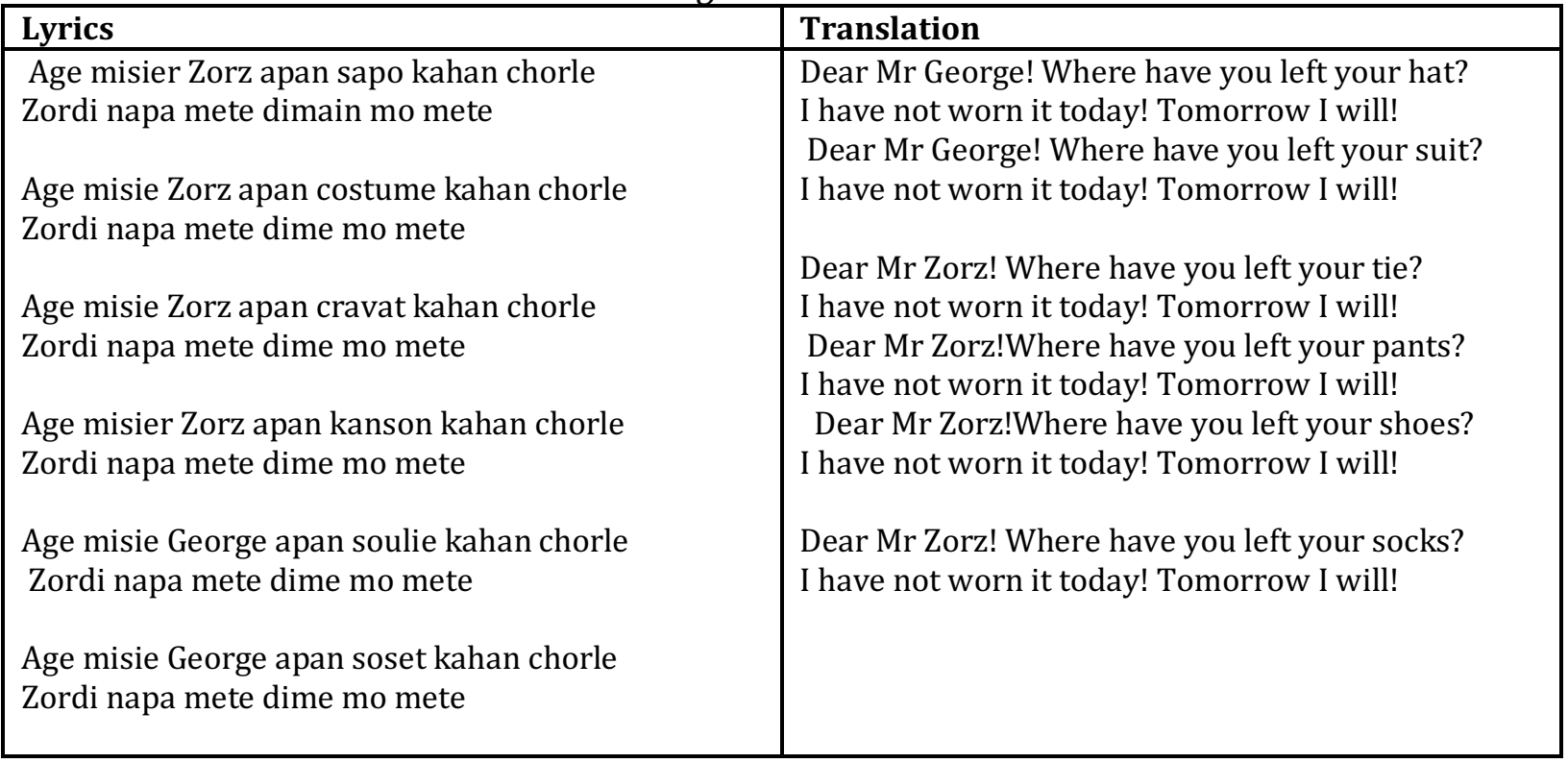

Normally, Jhoomar songs describe the Hindu woman's fondness for jewelry, beautiful dresses and have exquisite pieces on love themes. In this song, we assist a reverse in the gender empowerment issue. Normally, in almost all the Jhoomar of the Bhojpuri folk songs, the content rotates along feminism. According to one of the informants, Mrs Anumada, 'I would never have thought that one day in Geet Gawai we will be performing on such a song where we are describing the different items worn by a man!'

In this song, Mr George is at the center of attraction, about his hat, suit, tie, pants, socks and shoes. Long ago, there use to be a song on the wears of grand father and father where mention was made of pagri-wearing of the tradition turban and dhoti- loin cloth. According to Mrs Anumada, these have been replaced by 'sapo'-hat and 'kanson'-pants; having the influences on the Western Culture.

Indeed, in the recent Jhoomar songs, we assist the presence of creole words which have beautifully integrated the Mauritian Geet Gawai. Nowadays it has become an acceptable practice in the Mauritian culture to sing Bhojpuri song with inclusion of creole words. This song has the second line completely in creole: zordi napa mete, dime mo mete (I have not worn it today. Tomorrow I will.)

\section{Recurrent Ideas}

\subsection{DISCUSSION}

\subsubsection{Categories of recurrent ideas and practices in the songs}

The above translation and summary allow us to regroup the prevalent ideas into 'umbrella' categories, as follows:

\subsubsection{Expressions of emotions}

In all the Jhoomar songs, expressions of joys and happiness are seen. According to Sarita Boodhoo, these songs are loaded in meaning with erotic sentiments and are extremely sweet and melodious. They are sung on happy occasions as a means of entertainment. Some are hilarious pieces and 
others are erotic in essence. They use a lot of abusive words lovingly and have great fun in the process. A lot of fun is shared. They do mock marriage items. The women dance in a circular motion swinging the hips and the hands. Old, young, idle-aged all join in. it is indeed a hilarious moment. As the climax is reached more and more spicy pieces are sung from the women's unbelievable repertoire usually colorful as they are spicy.

\subsubsection{Sociological evolution: Continuity and Change}

The concept of 'Continuity and Change' is present in the analysed songs. Cultural, social and economic evolutions have taken place in the Mauritian Jhoomar.

- The performance of Geet Gawai on a voluntary basis is completely vanishing. The group are booked in advanced and paid fully with transport facilities being provided as per Mr. Aditya.

- Long ago, no men were admitted inside. However, during the last decade and with the nomination of the Geet Gawai by UNESCO since December 2016, it has become accessible to each and every one. There is no longer restriction for males to attend. The gendered socialization is today seen.

- Men are also singing and dancing as performers in the groups. Both males and females are teaming together either as singers, musicians or dancers for their economic growth.

- Dholok, lota(water container), spoon, coins, jhaal(cymbals), manjira (small cymbals), wood are continuously being used. Added to these, today there are also other instruments being used when the Jhoomar songs are performed like dhol-big Indian double headed drum, ravanne-large tambourine-like instrument used in sega music in Mauritius, djembe- a ropetuned skin covered goblet drum played with bared hands originally from West Africa which in the eighties were never played. These African instruments have integrated the Bhojpuri culture, strengthening its popularity among the youth mostly as per Aditya.

- During a 'Geet Gawai' session, the traditional wear remains the Indian saree. However, there is also a change to 'lehenga choli'- (blouse and skirt). Jewels like 'mang tikka'(Indian hair ornament), earrings, bangles, anklets are continuously worn. Newly added to these is the belly dancing belts with coins like Arabian Belly Dancers which embellish their performances. It is used by both male and female dancers.

\subsubsection{Use of Creole words}

The change can be observed in terms of changing vocabulary as well. One can see usage of Creole words in Bhojpuri folksongs. This change can be attributed to several factors, one being the singers themselves use the Creole language to communicate in their daily lives. Besides, there is also a cultural acceptance of Creole words as a sense of patriotism as most of the Mauritian has it has his mother language. Words like 'sapo', 'cravat', 'soset', 'soulier', 'lecourse' have easily been assimilated in the Bhojpuri culture. Besides, the word 'Jani coco' which means 'lover' is often used and has already been accepted in the Bhojpuri vocabulary. The sociolinguistic analysis of the creole words used in these Mauritian Jhoomar depict cultural assimilation. Mauritius being a rainbow nation with people of different faith around the world has a culture of tolerance and assimilation. There are some songs where the whole line is in Creole.

The song 'Age Misie Zorz', according to Mrs Manaram, is about an English Gentlemen who normally would wear his hat, suit with ties and shoes. And he would even attend Hindu wedding ceremonies in the village whenever he was invited. One day he jokingly asked one Githarinn : "You sing for 
Dawosing, J. (2020). A Sociological Analysis of Bhojpuri Jhoomar in Mauritius. Advances in Social Sciences Research Journal, 7(5) 230-239.

everyone except me! You never mention me in any of your song!" And the Githarinn indeed felt bad and in the following wedding, she composed that song for Mr George. 'George' is a Greek word which means 'farmer, earth worker'. And the Indian immigrants were brought to work the soil as cane cutters! According to Ramyead, the position of Bhojpuri language by 1900, can be summarized as follows:(1988: 31-34):

- Mauritian Bhojpuri had undergone a process of homogenization resulting in a 'more or less standardized and mutually intelligible language, a unified Bhojpuri.

- Mauritian Bhojpuri had also incorporated many Creole words

- Most of the Indians in Mauritius were by that time generally able to converse in Creole, although their phonetics were affected by the respective Indian languages they spoke.

Furthermore, according to Shameem Oozeerally (2013), in Mauritius one of the languages which have known considerable decline over the years is Bhojpuri. According to Stein (1982), only two languages have a Mauritian character: Creole and Bhojpuri. Hence, the presence of Creole words in Mauritian Bhojpuri songs is an automatic assimilation which only embellishes the Jhoomars.

\section{CONCLUSION}

Contemporary musical discourse is of utmost interest. Bhojpuri music is getting more and more vibrant today. The rhythmic melodious Bhojpuri Jhoomar during the pre-wedding ceremonies is becoming more and more popular. The custodians who have preserved these songs as the tradition bearers. They have kept alive these songs through memory and throat. The modern Githarinn are innovative. Jhoomar an originally woman's affair has become public. It is performed on the Mauritian beaches just like the typical sega songs. It is broadcast on local television. This implies the evolution of the women breaking the shackles of the confined four walls of the house. This ceremony depicts that there are no barriers of caste and class as it contributes in the making of a strong multiracial community identity. (Dawosing, 2019). Change in their clothing, ascessories worn by women and cosmetics extensively used is indicative of their good economic conditions. Together with the traditional, they know well how to adapt the lyrics to contemporary issues and make them relevant. The analysed Mauritian Jhoomar songs showed how their creativity have perpetuated a living tradition. They are creative during competition, active on social media, make use of every possible tool to popularize their 'business'. The modern Geet Gawai has today opened its doors and windows not only to males but also to other cultures without losing ground in its own roots and traditions.Addition of more instruments has been feasible also through better financial situations. In a multi-racial island, maintaining peace and harmony is not always easy. However, as a powerful unifier, the Geet Gawai through its Jhoomar songs has popularized and valorize not only Indian culture but European and African cultures as well.

\section{SCOPE OF FUTURE RESEARCH}

The Mauritian Jhoomar songs in Mauritius are quite old and a comparative study between the two would be interesting. A stronger comparison using synchronic and diachronic approach that is by comparing between the 10 contemporary jhoomar under study and some popular jhoomar of the past.

\section{References}

Aleshinskaya E. (2014), Key Components of Music Discourse Analysis in Research: Research in Language

Baker P. (1984)-Language in Society, cambridge.org 
Bhalla, P (2006) Hindu Rites, Rituals, Customs \& Traditions

Bhojpuri folk songs in Mauritius, Geet-Gawai-intangible heritage-Culture Sector-UNESCO http://ich.unesco.org

Boodhoo S, (1993) Kanya Dan, The Why's of Hindu marriage Rituals-Mauritius Bhojpuri Institute

Boodhoo S, (1999) Bhojpuri Traditions in Mauritius, Mauritius Bhojpuri Institute

Dawosing, J. (2019). The Psychology of Worship in the Mauritian Bhojpuri Folk songs. PEOPLE: International Journal of Social Sciences, 4(3). Retrieved from https://grdspublishing.org/index.php/people/article/view/1756

Economic impact assessment of the Mauritian horse racing industry -Supertote

https ://supertote.mu. Retrieved 25 Nov 2019

Harris, Marvin. The Rise of Anthropological Theory: A History of Theories of Culture. New York: Thomas Y.Crowell, 1968.

Hosseini, A., \& Sattari, E. (2018). A review of Naguib Mahfouz's review'The Beggar' based on Norman Fairclough's Critical Discourse Analysis. PEOPLE: International Journal of Social Sciences, 4(1). Retrieved from https://grdspublishing.org/index.php/people/article/view/1303

Jayawardena, Chandra.(1968) “ Migration and Social Change: A survey of Indian Communities Overseas.”

Kondapi, C. 1951.Indian Overseas, 1838-1949.Bombay:Oxford University Press

Manuel, Peter (1997) “Music, identity and images of India in the IndoCaribean diaspora." Asian Music: 17-35.

Murphey, Tim. (1992), The discourse of pop songs." Tesol Quarterly 26.4: 770-774.

Musical thing to do in Mauritius: attend a Geet Gawai-My Moris http://mymoris.mu

Myers H. (1998) Music of Hindu Trinidad-Songs from the India Diaspora". The University of Chicago Press-LTD-

London

Oozeerally S. (1999)The Evolution of Mauritian Bhojpuri: AN Ecological Analysis. Retrieved 25 Nov 2019

Ramdin S.(1989). Sanskar Manjari, Mahatma Gandhi Institute

R.E. Sullivan (1982) “John Toland and the Deist controversy: A Study in Adaptations”, Harvard University Press, p.193

Singh A, 1997- Folksongs as an Epistemic Resource: Understanding Bhojpuri Women's

Articulations of Migration-Tata Institute of Social Sciences, Patna Centre

Takshila Campus-DPS Senior Wing, Village: Chandmari, Danapur Cantonment

Patna - 801502 (Bihar) INDIA

Souvenir Magazine 2014.pdf Aapravasi Ghat Trust Fund

www.aapravasighat.org. Retrieved 25 Nov 2019

The Hazards of Gambling :Volume11 Issue 4

www1.cs.columbia.edu 